\title{
Stem Cells in the Intestine: Possible Roles in Pathogenesis of Irritable Bowel Syndrome
}

\author{
Sutheera Ratanasirintrawoot ${ }^{1,2}$ and Nipan Israsena ${ }^{1,3 *}$ \\ ${ }^{1}$ Stem Cell and Cell Therapy Research Unit, Chulalongkorn University, Bangkok, Thailand; and Departments of ${ }^{2}$ Research Affairs and \\ ${ }^{3}$ Pharmacology, Faculty of Medicine, Chulalongkorn University, Bangkok, Thailand
}

Irritable bowel syndrome is one of the most common functional gastrointestinal (GI) disorders that significantly impair quality of life in patients. Current available treatments are still not effective and the pathophysiology of this condition remains unclearly defined. Recently, research on intestinal stem cells has greatly advanced our understanding of various $\mathrm{Gl}$ disorders. Alterations in conserved stem cell regulatory pathways such as Notch, Wht, and bone morphogenic protein/TGF- $\beta$ have been well documented in diseases such as inflammatory bowel diseases and cancer. Interaction between intestinal stem cells and various signals from their environment is important for the control of stem cell self-renewal, regulation of number and function of specific intestinal cell types, and maintenance of the mucosal barrier. Besides their roles in stem cell regulation, these signals are also known to have potent effects on immune cells, enteric nervous system and secretory cells in the gut, and may be responsible for various aspects of pathogenesis of functional GI disorders, including visceral hypersensitivity, altered gut motility and low grade gut inflammation. In this article, we briefly summarize the components of these signaling pathways, how they can be modified by extrinsic factors and novel treatments, and provide evidenced support of their roles in the inflammation processes. Furthermore, we propose how changes in these signals may contribute to the symptom development and pathogenesis of irritable bowel syndrome.

(J Neurogastroenterol Motil 2016;22:367-382)

Key Words

Intestinal stem cells; Irritable bowel syndrome; Notch; Transforming growth factor beta; Wnt

\section{Introduction}

The intestinal epithelium acts as a protective physical barrier and fulfills secretory and absorptive functions required for digestive activity. Intestinal tissue needs to be highly regenerative in order to maintain homeostasis as well as to repair damage incurred by constant physical, chemical, and biological challenges. Our knowledge of intestinal stem cells (ISCs), their roles during homeostasis and regeneration, and the signaling pathways governing their renewal and fate choices, has shed some light on molecular mechanisms underlying pathophysiological features observed in patients with gastrointestinal (GI) diseases. Here we review recent advances regarding the identity of ISC populations, intrinsic and extrinsic factors regulating stem cell fate during homeostasis and regeneration following injury, and the involvement of stem cell dysregulation in the pathogenesis of irritable bowel syndrome (IBS). As low grade inflammation has been one of the major factors in pathogenesis of

Received: February 4, 2016 Revised: None Accepted: March 8, 2016

(c) This is an Open Access article distributed under the terms of the Creative Commons Attribution Non-Commercial License (http://creativecommons. org/licenses/by-nc/4.0) which permits unrestricted non-commercial use, distribution, and reproduction in any medium, provided the original work is properly cited.

*Correspondence: Nipan Israsena, MD, PhD Department of Pharmacology, Faculty of Medicine, Chulalongkorn University, 1873 Rama IV rd., Lumpini, Pathumwan, Bangkok 10330, Thailand Tel: +66-256-4000 (ext. 4481), Fax: +66-256-4000 (ext. 4481), E-mail: nipan.i@chula.ac.th 
IBS, knowledge on the roles of stem cells in inflammatory bowel disease (IBD) may provide insights into the pathogenesis of IBS. Advanced knowledge of the dynamic cross-talks between multiple signaling pathways governing stem cell fate choice and plasticity will transform our understanding of the pathophysiology of IBS and other functional gastrointestinal (GI) disorders, and introduce novel therapeutic approaches aiming to modify cellular processes necessary for tissue repair and regeneration.

\section{Different Functions of Intestinal Cell Types}

The intestinal epithelium requires two major cell lineages; absorptive and secretory, to satisfy diverse roles (Fig. 1). Absorptive enterocytes facilitate digestion and absorption as well as contribute to barrier functions by maintaining tissue integrity and host defense. ${ }^{1}$ Tight junctions near the apical surface of enterocytes help prevent entry of infectious agents and antigens. Enterocytes sense bacteria by means of pattern recognition receptors such as Toll-like receptors. Depending on the situation, enterocytes can produce a wide range of cytokines including pro-inflammatory TNF- $\alpha$, IL$1 \beta$, IL-6, as well as suppressive cytokines such as IL-10 and TGF$\beta$, which can act on resident immune cells and modulate mucosal immune responses. ${ }^{2}$

Secretory cell lineage subdivides into goblet cells, Paneth cells, and enteroendocrine cells. Goblet cells produce mucins to form a protective luminal mucus layer. ${ }^{3}$ Paneth cells secrete anti-microbial peptides such as $\alpha$-defensin 5 and 6 (HD5 and HD6) as well as other signal molecules that are required for gut homeostasis. ${ }^{4,5}$ Enteroendocrine cells secrete multiple regulatory molecules which control important physiological functions such as GI motility, biliary and exocrine pancreas secretion, digestion and intestinal epithelial renewal. Molecules released by these endocrine cells include serotonin (5-HT), cholecystokinin (CCK), ghrelin, gastrin-releasing peptide, glucose-dependent insulinotropic peptide, secretin, peptide YY, glucacon-like peptide-1, glucacon-like peptide-2, neurotensin, substance P, somatostatin, and motilin. Several of these molecules have been found to associate with functional gastrointestinal disorders and their symptoms such as IBS and functional dyspepsia. ${ }^{6-8}$ These cells interact and integrate with the enteric nervous system, a complex network of neurons and glia distributed throughout the gut wall, which regulates most aspects of intestinal functions.

Recently, it has been shown that different cell types underneath the intestinal epithelial layer, such as stromal cells, immune cells, and enteric glia, provide important signals involved in regulating intestinal epithelial homeostasis/repair and modulating sensitivity of the enteric nervous system. ${ }^{10}$ Intestinal stromal cells can sense pathogens and modulate immune/tissue response by providing a variety of mediators, including Wnts, Wnt antagonists, fibroblast growth factor, as well as inflammatory (IL-1 $\beta, \mathrm{TNF}-\alpha$, and granulocyte-macrophage colony-stimulating factor and anti-inflammatory cytokines (TGF- $\beta$ and IL-10). ${ }^{11,12}$ The interaction between epithelial cells and resident immune cells, such as macrophages and Tlymphocytes, are crucial in the regulation of intestinal cell prolifera-

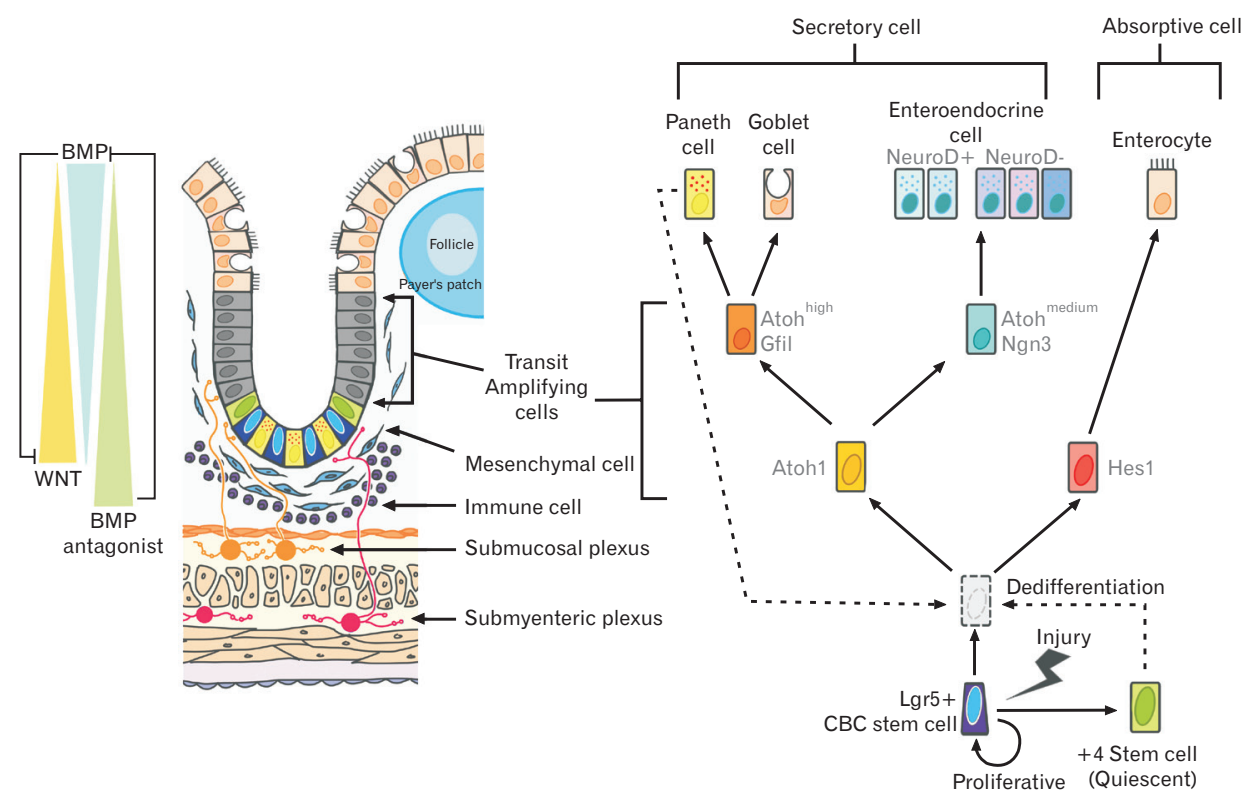

Figure 1. Intestinal epithelium: cellular components, their anatomical positions and key transcription factors for their fate specification. Two types of stem cells reside in the intestinal crypt- $\mathrm{Lgr} 5$ expressing crypt base columnar (CBC) stem cell (purple) and +4 stem cell (green). Cell fate specification of stem/ progenitor cells to either secretory or absorptive lineage relies on appropriate level and proper temporal expression of key transcriptional regulators (written in grey). Stem cell maintenance and fate decision is governed by signaling pathways such as Notch, Wnt and bone morphogenic protein (BMP). Recent reports suggest that differentiated secretory cells and +4 stem cells may dedifferentiate to replenish stem cell/progenitor pool during injury. 
tion and differentiation. ${ }^{13,14}$ Rag1 ${ }^{-/}$mice, which lack lamina propria lymphocytes, exhibit intestinal epithelial defects. ${ }^{15}$ Enteric glial cells are involved in the maintenance of mucosal integrity. Moreover, it produces nerve growth factor (NGF), glial cell-derived neurotrophic factor (GDNF), and TGF- $\beta$, which can modulate visceral sensitivity. In IBD, copious evidence links the abnormalities of these signals to IBD pathogenesis. ${ }^{16}$ It is possible that the disturbance in these development/repair signals could contribute to the pathogenesis and symptom development in patients with functional GI disorders, and understanding their functions could lead to new therapeutic interventions.

\section{Identification of Intestinal Stem Cells and Their Roles in Maintaining Tissue Homeostasis and Regeneration}

To maintain intestinal homeostasis, cells lost during daily wear and tear need to be constantly replenished. In fact, intestinal tissue has the most rapid cellular turnover, and complete renewal of the epithelium occurs within 3-5 days. ${ }^{17}$ Such an astounding rate of repopulation can be achieved by the proliferation of ISCs located in the crypt. Their progenies gradually move up towards the villi and differentiate into absorptive or secretory lineages. As gradients of multiple signaling molecules exist along the crypt-villi axis, positions of stem/progenitor cells affect their stem/progenitor identity as well as their cell fate decision. ${ }^{18,19}$

Within the crypt, two populations of ISCs have been identified. The first proposed stem cells, crypt base columnar (CBC) cells, reside within the base of the crypts and express Lgr5 (Fig. 1; in purple). ${ }^{20}$ The Lgr5 + CBC cells have been shown to long-term self-renew and differentiate, giving rise to all cell lineages in the intestinal epithelium in vivo. ${ }^{21}$ In vitro, a single Lgr5 + stem cell can form self-organizing three dimensional crypt-like structures termed "organoids" composed of all intestinal cell types. ${ }^{22}$ An alternative population of label-retaining stem cells was identified at the +4 position from the crypt base (Fig. 1; in green). ${ }^{23}$ These so-called +4 stem cells resided in a niche distinct from $\mathrm{CBC}$ cells and were shown to be slow-cycling, contrasting to $\mathrm{CBC}$ cells which are actively-cycling. The +4 stem cells can give rise to Paneth and enteroendocrine cells, thus appearing more-lineage restricted compared to $\mathrm{CBC}$ cells. ${ }^{24-26}$ Functions and involvement of +4 stem cells during homeostasis vs injured state and their roles in GI diseases are still poorly understood.

It is only recently that the much debated nature of the 2 stem cell populations and their relationship has been somewhat resolved.
Lineage tracing experiments showed that all cell types are derived from the actively-cycling Lgr5 + CBC cells during homeostasis, ${ }^{21}$ including the quiescent +4 stem cells. ${ }^{27}$ Upon physical, chemical, or biological insults that deplete $\mathrm{CBC}$ cells, +4 stem cells and lineage-restricted secretory progenitors dedifferentiate to replenish the active stem cell pool in the tissue. ${ }^{28-32}$ Instead of a model where classical quiescent non-committed stem cells on the top of the hierarchy produce actively-cycling stem/progenitor cells during injury, regeneration of intestinal epithelium is dependent on the plasticity of some slow-cycling progenitors and post-mitotic differentiated cells acting as facultative reserve stem cells. The degree of such plasticity and the mechanism of +4 stem cell activation remains unclear. The population of stem cells activated and the manner of activation might differ in homeostasis, compared to injury or disease conditions. Understanding factors contributing to failure of stem cell maintenance and its reactivation upon damage would help explain the pathogenesis of GI disorders such as its role on maintaining low grade inflammation, altered gut sensation and gut dysmotility.

\section{Cell Fate Determination Is Tightly Regulated by Intrinsic Factors Such as Basic Helix-Loop-Helix Transcription Factors}

Maintenance of stem cell functions during homeostasis and mobilization of intestinal cells to repopulate the damaged tissue during the regenerative process depends on both cell intrinsic properties and signals from the microenvironmental niche. Anatomically, ISCs are restricted to the crypt base area dubbed the "stem cell zone," where Paneth cells and the surrounding mesenchyme provide signals influencing the stem cell identity and functions. ${ }^{33}$ Stem cells' progenies compete for restricted niche space at the crypt base. The niche-associated daughter cell retains stem cell fate, while the sister cell adopts alternative fates. Subsequent decisions between secretory and absorptive cell fates in progenitor cells appear intrinsically dependent upon cell autonomous expression of certain key transcription factors.

The basic helix-loop-helix (bHLH) transcription factors are known to govern cell fate identity. The complex specification process generally requires both individual and combinational coding (Fig. 1; written in grey). ${ }^{34}$ Members of the bHLH family, particularly mouse atonal homolog 1 (Math1), neurogenin3 (Neurog3), and NeuroD, play prominent roles in intestinal cell fate specification. ${ }^{35}$ Acting at different stages during the differentiation process, these 3 bHLH transcription factors together guide cells along secretory fate towards endocrine lineage. Math1, alternatively known 
as Atoh1, specifies secretory progenitor cell fate. ${ }^{36}$ Mice deficient for Math1 fail to generate goblet cells, Paneth cells, and enteroendocrine cells. Conversely, Math1 expression is sufficient to drive secretory differentiation at a cost of absorptive fate. ${ }^{37}$ The concomitant loss of enterocytes observed with secretory cell expansion suggests that Math1 alters fate choice of bipotential progenitor cells.

Cells in secretory lineages are further specified by a transcriptional repressor, growth factor independent 1 (Gfi1). ${ }^{38}$ Loss of Gfil in mice results in a lack of Paneth cells, a reduced number of goblet cells and a dramatic expansion of enteroendocrine cells, suggesting its normal influence towards Paneth and goblet fates. Notably, Gfi1 needs to be subsequently down regulated for cells to proceed to a terminally differentiated state. Homeodomain transcription factors Arx and Pax4 are shown to be involved in enteroendocrine subtype specification. In Pax4 knockout mice, the differentiation of 5-HT, somatostatin, insulinotropic peptide, and gastrin cells are impaired. ${ }^{39}$

The intestinal epithelium comprises numerous subtypes of enteroendocrine cells, expressing different combination of neuropeptides. ${ }^{40}$ Once the subtypes are established, the cells stably maintain their committed fates, albeit further exposure to external stimuli. Neurog3, transiently expressed in precursor cells, is a transcription factor essential for enteroendocrine cell fate specification. ${ }^{41}$ Overexpression of Neurog3 leads to expansion of enteroendocrine cells coupled with reduction of goblet cell number, but not overall secretory cell number. ${ }^{42}$ The later stage of differentiation is facilitated by additional regulators. NeuroD is found to be important for secretinexpressing enteroendocrine cells as it coordinates their cell cycle arrest and terminal differentiation. ${ }^{43}$ Still, the exact subtypes specified by NeuroD remain controversial. Taken together, the bHLH transcription factors function as intrinsic regulators of intestinal cell fate determination.

In addition, these transcription factors sequentially regulate expression of other transcriptional regulators. Math1 is found to be upstream of Gfil and Neurog3 while NeuroD is directly downstream of Neurog $3{ }^{44}$ Understanding this intricate circuitry is crucial as an imbalance in cellular composition has clinical implications. A mutation in NEUROG3, for example, causes reduced density of enteroendocrine cells and has been reported in congenital malabsorptive diarrhea and post intestinal allograft rejection. ${ }^{45,46}$

\section{Signals from a Microenvironmental Niche Direct Intestinal Stem Cell Renewal and Fate Specification}

In addition to intrinsic factors, extrinsic signals play critical roles in stem cell renewal and differentiation. As mentioned, ISCs reside in their microenvironmental niche, the crypt. This allows them to receive signaling molecules from many cell types, including adjacent Paneth cells and subcrypt mesenchymal cells. ${ }^{5,47}$ As distinct cell types express different ligands and receptors, spatial location of various specialized cell types as well as stem cells in relation to one another is very important for intestinal cell growth, survival and fate specification. Wnt/R-spondin, Notch, and TGF- $\beta /$ bone morphogenic protein $(\mathrm{BMP})$ are major pathways known to regulate stem cell maintenance and differentiation. ${ }^{48-50}$

\section{Notch Signaling Pathway}

Notch pathway signals via a direct cell-to-cell contact. In the mammalian intestine, membrane-bound Notch ligands (Dll1 and Dll4) from one cell bind to transmembrane Notch receptors on the surface of the adjacent cell to activate the signaling cascade (Fig. 2A). ${ }^{19,50}$ The extracellular portion of bound receptors is proteolytically cleaved by a disintegrin and metalloprotease (ADAM)/TNF$\alpha$ converting enzyme (TACE) followed by intramembrane cleavage by gamma secretase. The active Notch intracellular domain is released and subsequently translocates into the nucleus to activate downstream targets such as Hes which represses multiple genes, including secretory fate-promoting Math $1 .{ }^{51}$ Notch signaling inhibits expression of cyclin-dependent kinase p27Kip1 and p57Kip2 in intestinal progenitors therefore maintains them in a proliferating state. $^{52}$

Notch can be further modulated by various ubiquitin ligases, deubiquitinating enzymes and endocytosis mediators, many of which also form feedback loops with the Notch pathway. ${ }^{52}$ With its function in stemness maintenance, and secretory fate suppression, loss of Notch signaling reportedly leads to precocious stem cell differentiation towards secretory lineage, especially the goblet cell population. ${ }^{53,54}$ Notch signaling is also involved in the maintenance of tight junction and mucosal immune response. ${ }^{55,56}$ Without proper Notch signaling, the stem cell pool and the compositional balance of cell types cannot be maintained, resulting in disrupted intestinal barrier and inflammation.

Many components of the Notch signaling cascade can be modulated by extrinsic factors. Mice with deletion of protein O-fucosyl transferase 1, a glycosylation enzyme which is required for Notch ligand binding, exhibit secretory cell hyperplasia and chronic intestinal inflammation. ${ }^{19,57}$ After injury/inflammation, up-regulation of Notch signaling is required for intestinal epithelial repair. ${ }^{58}$ Inactivation of Notch signaling through the deletion of metalloprotease 
A

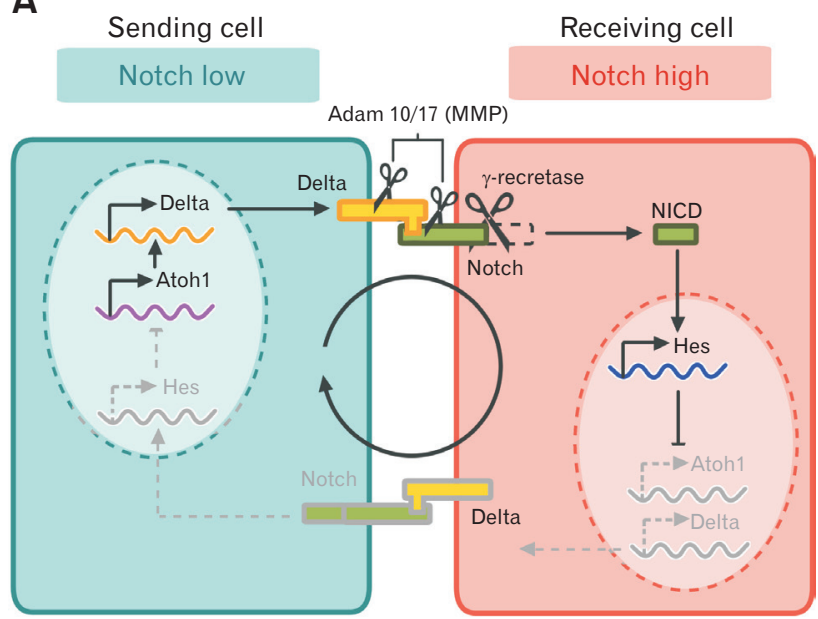

B

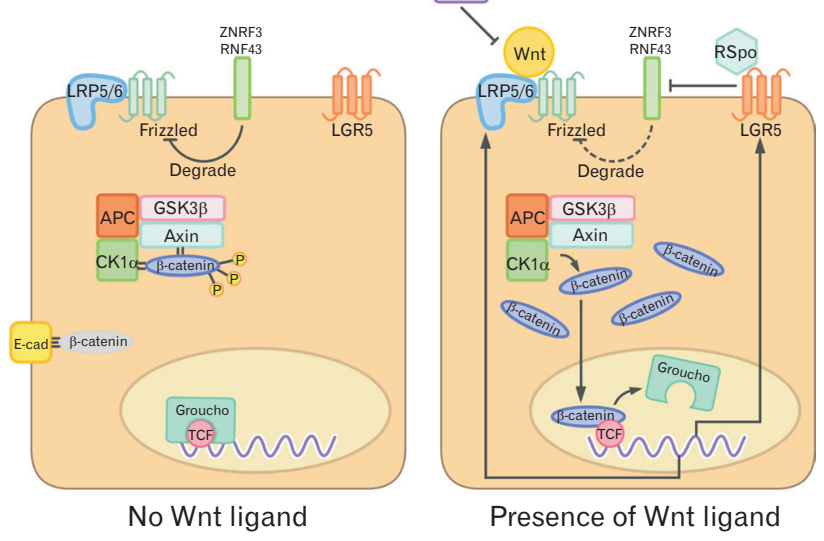

Figure 2. Signaling pathways important for stem/progenitor cells regulation. (A) Notch signaling pathway. Cell-cell interaction is required for lateral inhibition. The sending cell produces Delta which binds and activates Notch in the adjacent cell. Matrix metalloproteinases (MMPs) such as Adam10 and Adam 17 proteolytically cleave Notch extracellular domain while gamma secretase cleaves intracellular domain, leading to transcriptional activation of Notch target genes which feedback to inhibit Notch in the sending cell. (B) Wnt signaling pathway. In the absence of ligand (left), $\beta$-catenin is inhibited by the destruction complex. Binding of Wnt ligand to receptors frees $\beta$-catenin which displaces the transcriptional repressor Groucho. Together with the $\mathrm{T}$ cell factor (TCF) transcription factor, $\beta$-catenin activates Wnt target genes including some of its own receptors. Of note, R-spondin can potentiate Wnt signaling through inhibiting ZNRF3/RNF43 which normally inhibits the Wnt transmembrane receptor Frizzled. DKK, Dickkopf.

Adam10, transcription factor Hes1, or both Notch1 and Notch2 receptors, the inhibition of gamma-secretase, or the expression of Notch antagonist Numb, resulted in loss of regenerative response in the intestinal epithelium. ${ }^{52,53,58-61}$ Distinct Notch ligands may play different roles in the normal and the inflamed intestinal mucosa. ${ }^{62}$ Although deletion of Dll4 alone has no effect on intestinal epithelium, Dll1 and Dll4 double knockout converts all proliferating progenitors into goblet cells. ${ }^{50}$ In dextran sulfate sodium-induced colitis, the number of Dll4+ cells is significantly increased, while Dll1 + intestinal epithelial stem cells decrease compared to the normal colon. It is possible that Dll4 is a more prominent ligand during injury/repair.

Expression and activity of enzymes required for Notch cleavage is also found to be modulated by various extrinsic factors. ${ }^{63}$ The transcription of ADAM 10 can be stimulated by retinoic acid, while cholesterol depletion leads to enhancement of its enzymatic activity. Although ADAM10 is essential in ligand-dependent Notch signaling, other metalloproteases such as ADAM17 can also cleave Notch in the absence of ligand. ${ }^{64}$ ADAM17 is post-transcriptionally up-regulated in inflamed colon epithelium and is shown to be crucial for cleavage of TNF- $\alpha$ and epidermal growth factor receptor, which are important cytokines during inflammation. ${ }^{65}$ Thus, in situations of chronic inflammation, Notch signals are dysregulated and may act in a ligand-independent way. Notably, metalloprotein- ase 3 , a target of TGF- $\beta$, can also inhibit ADAM17. ${ }^{65}$ Pharmacological inhibition of ADAM 17 amplified TNF- $\alpha$-mediated gut mucosal hyperpermeability. ${ }^{66}$ Thus, cross-talk between components of Notch signaling and inflammatory signals influences the level of Notch signaling and vice versa.

\section{Wnt Signaling Pathway}

Both canonical and non-cannonical Wnt signaling play integral roles in ISC proliferation, maintenance, and secretory fate decision. ${ }^{67,68}$ Wnt ligands bind to the Wnt transmembrane receptors Frizzled $(\mathrm{Fz})$ as well as Wnt co-receptors Lrp5/6 on the target cells, triggering formation of a large protein complex, which includes glycogen synthase kinase $3 \beta$, casein kinase 1 , and scaffolding proteins, adenomatous polyposis coli, Disheveled, and Axins (Fig. 2B). In the absence of Wnt, this complex phosphorylates the key effecter $\beta$-catenin, targeting it for proteosomal degradation. Wnt induction inhibits this destruction machinery, allowing $\beta$-catenin to displace a repressor, form a complex with $\mathrm{T}$ cell factor (TCF) transcription factor and together, transcriptionally activate Wnt targets. Such targets include Wnt pathway components Axin2 and Lgr5 as well as cell cycle genes c-Myc and $C_{y c}$ lin D1 ${ }^{69,70}$ Placing Wnt upstream of $T c f$, therefore, implicates the role of Wnt signaling in regulating Paneth cells positioning and differentiation. Loss of proliferative 
crypt and mispositioned Paneth cells can be observed upon deletion of Tcf4. ${ }^{71}$ Overexpression of the Wnt target gene Ascl2 induces the expansion of Lgr5 + stem cells and suggests that Ascl2 confers stemness. ${ }^{51,72}$ Overexpression of Dickkopf-1 (Dkk1), a Wnt antagonist, leads to a complete loss of secretory cells. ${ }^{68}$ Loss of proliferative crypt, inflammation, and a collapse of intestinal architecture is also observed with Dkk1 systemic expression. ${ }^{73}$ Therefore, mutations in Wnt signaling components including receptors can result in a dramatic loss of stem cell reserve and impaired post-injury regeneration. $^{11}$

Wnt can also signal in a $\beta$-catenin-independent fashion. Of the several Wnt ligands, Wnt3 can activate the canonical pathway and inhibit the non-canonical pathway, whereas Wnt5, which has shown to be associated with IBD, activates the non-canonical pathway. Non-canonical Wnt maintains quiescent stem cells during homeostasis, and upon injury, becomes attenuated while the Wnt canonical pathway activates stem cells for regeneration. ${ }^{74-76}$ In vertebrates, Wnt signaling can be further potentiated by the Wnt agonist R-spondin, which inhibits Rnf43/Znrf3. The ubiquitin ligases normally function to ubiqutinate and target Frizzled receptors for degradation upon its binding to Lgr receptors. ${ }^{77}$ Inhibition of Wnt negative regulators Rnf43/Znrf3 by R-spondin thus stabilizes Frizzled and augments Wnt signaling. As a Tcf transcriptional target, Lgr5 receptors are controlled by Wnt. Expression of Lgr5 in CBC stem cells, in turn, further sensitizes stem cell populations to Wnt signals. ${ }^{48}$ In accordance, Lgr4/5 deletion results in loss of proliferation and crypt integrity, a phenotype similarly observed in inactivation of Wnt signaling. ${ }^{48}$

Wnt ligands are expressed in different types of cells in the intestine, including Paneth cells and stromal cells. ${ }^{78}$ The main source of Wnt in vivo remains unclear. ISCs can be grown in long-term organoid culture without mesenchymal stromal cells when supplemented with R-spondin $1 .{ }^{22}$ In normal homeostasis, it has been proposed that the major source of Wnt comes from Paneth cells, which also provide Notch ligands. ${ }^{5}$ On the other hand, high Wnt is required for Paneth cell differentiation. Fate choice of secretory progenitor between goblet and Paneth cell fates can be influenced by MAPK signals by regulating $\mathrm{Wnt} / \beta$-catenin activity. ${ }^{79}$ During inflammation, Wnt is upregulated in the stromal cells, and intestinal immune cells and plays an important role in regulating stem cell proliferation and tissue repair. ${ }^{75,80}$ It is possible that stromal cells may be the major source that provides niche signals in the absence of epithelial Wnt. ${ }^{11}$ Bacterial and dietary or food factors have been reported to potentially affect Wnt signaling. Certain bacterial toxins such as clostridium toxin may attenuate Wnt signals, ${ }^{81}$ while high fat diet may increase level of Wnt signaling. ${ }^{82}$ Many Wnt antagonists are expressed in the intestine but their roles in homeostasis and pathological conditions have not been thoroughly explored. Deletion of Wnt antagonist Dkk1 in the intestine increase wound repair after experimental colitis. ${ }^{83}$

Dysregulated Wnt signaling may contribute to another aspect of GI disorder other than cell proliferation. For example, noncanonical Wnt has been shown to be capable of sensitizing sensory neuron to sub-threshold stimuli, which may contribute to enteric nervous system hypersensitivity observed in IBD and IBS. ${ }^{84}$

As discussed, both Notch and Wnt are critical for stem cell maintenance and differentiation, albeit directing towards opposite lineages. This opposition goes beyond simply specifying alternate fates. Rather, the extensive crosstalks between the 2 pathways regulate fate choices with fine balance. Inhibition of Notch pathway results in increased Wnt signaling followed by upregulation of prosecretory Wnt target genes such as Sox 9 and EphB3, leading to secretory cell hyperplasia. ${ }^{85}$ This suggests that in the normal context, Notch signaling dampens Wnt signaling and its role in secretory cell differentiation. Conversely, Wnt can also regulate Notch signaling, forming a negative feedback loop. The Wnt component Disheveled has been shown to bind and inactivate NICD as well as inhibit Notch ligand Delta. ${ }^{86,87}$

\section{Bone Morphogenic Protein/Transforming Growth Factor- $\beta$ Signaling}

Within the intestinal epithelium, multiple pathways co-regulate tissue renewal and repair. The TGF- $\beta$ plays important roles in the immune response as well as in tissue homeostasis and regeneration. TGF- $\beta$ superfamily encompasses several types of ligands, including TGF- $\beta 1-3$, Activin, Nodal and BMP. For the canonical pathway, TGF- $\beta$ superfamily ligands bind to the type II receptors which recruit and phosphorylate type I receptors together, forming a hetero-tetrameric receptor complex. The receptor binding results in phosphorylation and activation of receptor-regulated SMAD (RSMADs) such as Smad2/3, following TGF- $\beta$ /activin/nodal receptors activation. In cases of BMP, Smad1/5/8 are the R-SMADS phosphorylated. R-SMADs then bind with co-SMAD such as SMAD4. This R-SMAD/co-SMAD complex transcriptionally activates their target genes. Their targets control intestinal development, replication process of stem cells, and epithelial to mesenchymal transition (EMT) associated with chronic inflammation and fibrosis. ${ }^{88-90}$ In the intestine, BMP is highly expressed in cells at the luminal surface. 
Not only are BMP and Wnt ligands secreted from opposite ends of the intestinal villi-crypt axis, BMP can also suppress Wnt signaling through inhibition of $\beta$-catenin. ${ }^{91}$ Thus, BMP acts as a negative regulator of ISC self-renewal and proliferation, and promotes terminal differentiation of cells in secretory lineage. ${ }^{91,92} \mathrm{Ad}-$ ditionally, sub-crypt mesenchymal cells express BMP antagonists such as Gremlin and Noggin. The antagonists from the microenvironment, as seen in the case of mesenchymally-expressed Gremlin, suppress BMP and enhance Wnt function within the stem cell zone in the crypt. Ectopic expression of Gremlin promotes the maintenance of Lgr $5+$ stem cells that have exited the niche. ${ }^{93}$ Deletion of BMP components such as BMPR1A results in expansion of ISCs and impairment of differentiation to all three secretory cell types. ${ }^{94}$ Forced expression of Noggin, a BMP antagonist, resulted in de novo ectopic crypt-villus, reminiscent of human juvenile polyposis. $^{49}$

TGF- $\beta$ is an important cytokine involved in the regulation of many types of tissue specific stem cells. ${ }^{88}$ Its roles in the ISC niche have not been extensively investigated. However, it is known to be expressed in many types of cells in the intestine and crucial for modulating the immune response to gut flora and pathogens. ${ }^{95}$ The level of TGF- $\beta$ rises in the early phase of the injury/inflammation. ${ }^{96}$ TGF- $\beta$ can activate secretion of various cytokines from mesenchymal stromal cells and regulate gut resident immune cells. Strong TGF- $\beta$ can inhibit proliferation of intestinal epithelium and promote EMT. Similar to BMP, crosstalk between Wnt and TGF$\beta$ exists. Evidence suggests that $\mathrm{Wnt} 5$ a may exert suppressive effect on local epithelial cell proliferation during injury repair through TGF- $\beta$ signaling activation. ${ }^{74}$

\section{Inflammatory Bowel Disease}

IBD is an immune-mediated chronic intestinal condition which encompasses $\mathrm{CD}, \mathrm{UC}$, and unclassified IBD. Whereas CD mostly involves the distal ileum and/or the colon, the inflammation in UC is restricted to the colon. Although the pathogenesis of both $\mathrm{CD}$ and UC is still unclear, multiple lines of evidence suggest that IBD develops through an inadequately suppressed or exaggerated immune response to luminal antigen in genetically susceptible individuals. ${ }^{97,98}$ In this review we only briefly discuss on the involvement of ISCs and its regulatory signals in IBD pathogenesis and treatment.

Defects in stem cell differentiation towards Paneth cells in CD and towards goblet cells in UC have been gaining interest recently. Both goblet and Paneth cells defend intestinal epithelium against bacteria by secreting mucin and anti-microbial peptides, respec- tively. Reduced number or impaired function of these cells can thus lead to impaired barrier function, change in gut microbiota, and predisposes intestinal epithelium to inflammation. Indeed, mutations in MUC2 cause misfolding leading to ER stress in goblet cells followed by spontaneous inflammation. ${ }^{99}$

Deletion of Muc2 causes mice to develop spontaneous chronic colitis. ${ }^{100}$ Known IBD susceptibility genes expressed in Paneth cells include the intracellular bacterial-pattern recognition receptor $\mathrm{NOD} 22^{101,102}$ and the autophagy mediator ATG16L1 $1{ }^{103,104} \mathrm{Com}-$ mon pathologic findings in IBD are the depletion of goblet cells and mucus barrier. High Notch signals during tissue injury promote ISC self-renewal, and also enterocytes production at the expense of secretory cells. Notch signaling can inhibit MUC2 production through inhibition of the Math1 binding MUC2 promoter. ${ }^{105}$ Interestingly, inhibition of Notch signaling in the early stages of inflammation reduced the severity of dextran sulfate sodium-induced colitis probably through limited Notch effect on the reduction of secretory cells ${ }^{106}$ suggesting that modulation of notch signaling level at the appropriate time-window may provide beneficial effect.

Although it has been reported that expression of Wnts and Frizzled receptors are increased in the early stages of inflammation of IBD, long-term exposure of intestinal epithelial cells to IFN- $\gamma$ resulted in induction of the secreted Wnt inhibitor Dkk1. ${ }^{107}$ Thus, Wnt signaling may even be downregulated in chronic inflammation. Other than its function in maintaining ISC proliferation and regulating secretory cell potentials, Wnt signaling also affects Paneth cell function as Wnt is required for antimicrobial peptide defensin HD5 and HD6 expression. ${ }^{108}$ Wnt signaling is involved in gut inflammation and exerts both anti- and pro-inflammatory functions. ${ }^{109} \mathrm{Wnt}$ mediates its anti-inflammatory effects by inhibiting nuclear factor $\kappa \mathrm{B}$ activity, decreasing $\mathrm{TNF}-\alpha$ production and inducing expression of anti-inflammatory cytokines TGF- $\beta$ and IL-10. ${ }^{109}$ Noncanonical Wnt, however, can induce expression of inflammatory mediators ${ }^{110}$ and may contribute to hypersensitivity of enteric neuron by a separate mechanism. ${ }^{84,111}$ Nevertheless, it was reported that administration of a Wnt agonist activated the Wnt signaling pathway in the damaged mucosa and accelerated wound healing in a mouse model of colitis. ${ }^{14}$

With its roles in mucosal immunity and tolerance to normal flora, TGF- $\beta$ has been extensively studied in the context of IBD ${ }^{96,112,113}$ Although TGF- $\beta$ level is increased in CD and UC patients, signals downstream from the receptors were defective, leading to failure in controlling the inflammation. This is due to the up-regulation of Smad7 which inhibits TGF- $\beta$ signaling. ${ }^{114}$ The mechanism underlying the increase in Smad7 remains unresolved. 
Treatment with Smad7 antisense RNA was found to restore the ability of TGF- $\beta$ to suppress immune reactions of laminar propria mononuclear cells from IBD patients and in animal models of IBD. ${ }^{115,116}$ Phase II clinical trial of mongersen, an oral SMAD7 antisense oligonucleotide in patients with active $\mathrm{CD}$, demonstrates promising results. ${ }^{117}$ Patients who received mongersen had a significant rate of clinical response and remission than placebo. Interestingly, BMP antagonist Noggin is up-regulated in the early phase of colitis whereas treatment with BMP7 demonstrates anti-inflammatory effect on experimental IBD in rats. ${ }^{118}$ Thus, the strategy of
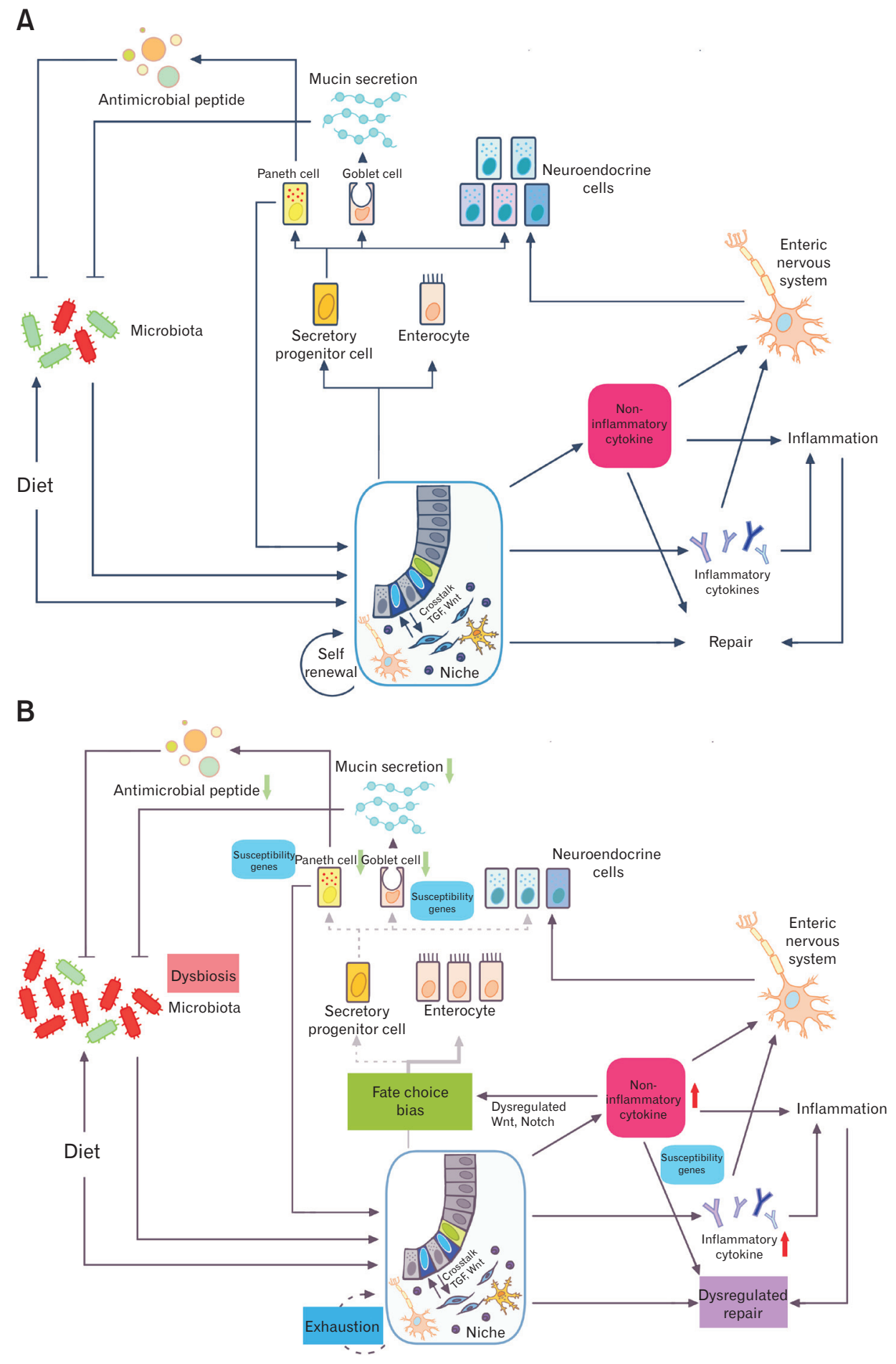

Figure 3. Pathogenesis of inflammatory bowel disease (IBD). (A) Interaction between external factors such as diet and microbiota and the cells of the intestine and enteric nervous system is depicted. Panel A shows regulatory circuitry during normal repair process. (B) Panel B shows disrupted system during dysregulated repair in IBD. Imbalanced microbiota and diet can affect stem cells and niche cells. The resulting increase in inflammatory cytokines and other signaling molecules leads to failure to maintain the stem cell pool, fate choice bias, and persistent inflammation. 
modulating TGF- $\beta /$ BMP may provide new therapeutic intervention for chronic gut mucosal inflammation or IBD.

Taken together, Notch, Wnt and TGF- $\beta /$ BMP signaling and some inflammatory cytokines play important roles in responding to external stimuli and maintaining stem cell number and function during intestinal homeostasis and repair (Fig. 3A). Imbalance of external factors such as diet and microbiota can result in dysregulation of inflammatory and non-inflammatory cytokines observed in IBD. Without proper signaling molecules, ISCs and niche cells cannot function reliably, leading to reduced number of intestinal cells, especially secretory cells, persistent activation of immune response, and hypersensitivity (Fig. 3B).

The establishment of long-term culture methods for ISCs raises the possibility that these cells may be used to promote mucosal healing in IBD patients with chronic ulcers. It was demonstrated that transplantation of either small intestinal organoids or fetal intestinal organoids can integrate into damaged mouse colon and form new functional crypts. ${ }^{119,120}$ Currently, ISC-based therapy is under development for treating IBD patients. ${ }^{121}$ In addition to ISCs, transplantation of other cell types that can modulate immune response has been developed into a potential therapy for IBD.

Mesenchymal stem/stromal cells (MSCs) are cells that can differentiate into mesenchymal cell lineage including bone, cartilage and fat. Cells that meet the criteria of MSCs defined by the International Society for Cellular Therapy (ISCT) can be isolated from various tissues including bone marrow, placenta, adipose tissues, amniotic fluid, and many other organs. Due to its ability to suppress the activity of immune cells, MSCs have been tested in many inflammatory diseases including IBD. ${ }^{122}$ Promising initial results have been published but so far have not been proven in phase III clinical trials. Furthermore, the mechanisms of immunomodulation of MSCs still need to be clarified.

\section{Irritable Bowel Syndrome}

IBS is a functional bowel disorder characterized by chronic abdominal pain or discomfort associated with altered bowel habits in the absence of specific pathological findings. IBS is one of the most common GI conditions in clinical practice. The pathophysiology of IBS is unlikely to be caused by a single mechanism. Genetic components, environmental factors (eg, diet and microbiota), activation of mucosal immune system/low-grade inflammation, altered gut motility, visceral hypersensitivity, neuroendocrine changes, and abnormalities in the brain-gut axis have been proposed as key contributors (Fig. 4). ${ }^{123-127}$ In this review, we focus on how signals related to stem cell homeostasis/repair may interact with the aforementioned mechanisms and contribute to symptom development and pathogenesis of IBS.

Compared to IBD, there is much less evidence of persistent activated immune cells or high levels of inflammatory cytokines in the bowel of patients with IBS. Nevertheless, in a significant number of IBS patients, mucosal biopsy revealed an increased number of mast and T-cell infiltration. ${ }^{128,129}$ Microscopic inflammation was also more frequently found in the IBS group than controls. More than $10 \%$ of IBS patients develop symptoms after an episode of acute gastroenteritis, which is called post-infectious IBS (PI-IBS). ${ }^{130,131}$ Peripheral blood mononuclear cells from patients with PI-IBS show $\mathrm{T}$ cell activation and an increased level of pro-inflammatory cytokines, including TNF and IL-6. ${ }^{132}$ Thus, at least in a subpopulation of patients with IBS, low grade immune activation is likely to contribute to the pathogenesis.

Increased mucosal permeability is frequently observed in IBS and can be caused by specific pathogens and diet (cow milk allergy or high fat diet), especially in patients with susceptibility genes. ${ }^{133,134}$ Activation of mucosal mast cells by short-chain fatty acid (through short-chain free fatty acid receptor 2 [FFA2]) and other stimuli triggers the release of specific proteases and inflammatory cytokines which further increase mucosal permeability. ${ }^{135}$ Dysregulated repair/ regenerative signals (Wnt, Notch, and TGF- $\beta$ ) could also contribute to the barrier leakage by their effects on cell-cell-junction, function and number of secretory cells and their indirect effects through immune cells. It is possible that alteration of these signals may persist even after inflammation subsides through epigenetic modification of their regulatory regions and target genes. ${ }^{136,137}$

IBS is subclassified into IBS-constipation predominant (IBSC), IBS-diarrhea-predominant (IBS-D), and IBS-mixed. Clinical presentation of each group shows some correlation with levels of 5-HT released from enterochromaffin cells, a major type of enteroendocrine cells in the gut. Recent findings suggest that 5-HT not only regulates gut motility but also plays a role in immune activation and inflammation. ${ }^{138}$ In patients with IBS-D, the level of circulating 5-HT was found to be increased, whereas decreased 5-HT was observed in IBS-C. ${ }^{139}$ Polymorphisms in the promoter of serotoninreuptake transporter genes have been reported to be associated with IBS-D risk. ${ }^{140}$ The alteration in the release of neuropeptides and hormones from enteroendocrine cells in IBS could be the result of the altered number of specific subtypes of enteroendocrine cells, abnormal enteroendocrine cell functions, and changes in sensitivity to stimuli.

Although it is still controversial, an alteration in the number of 


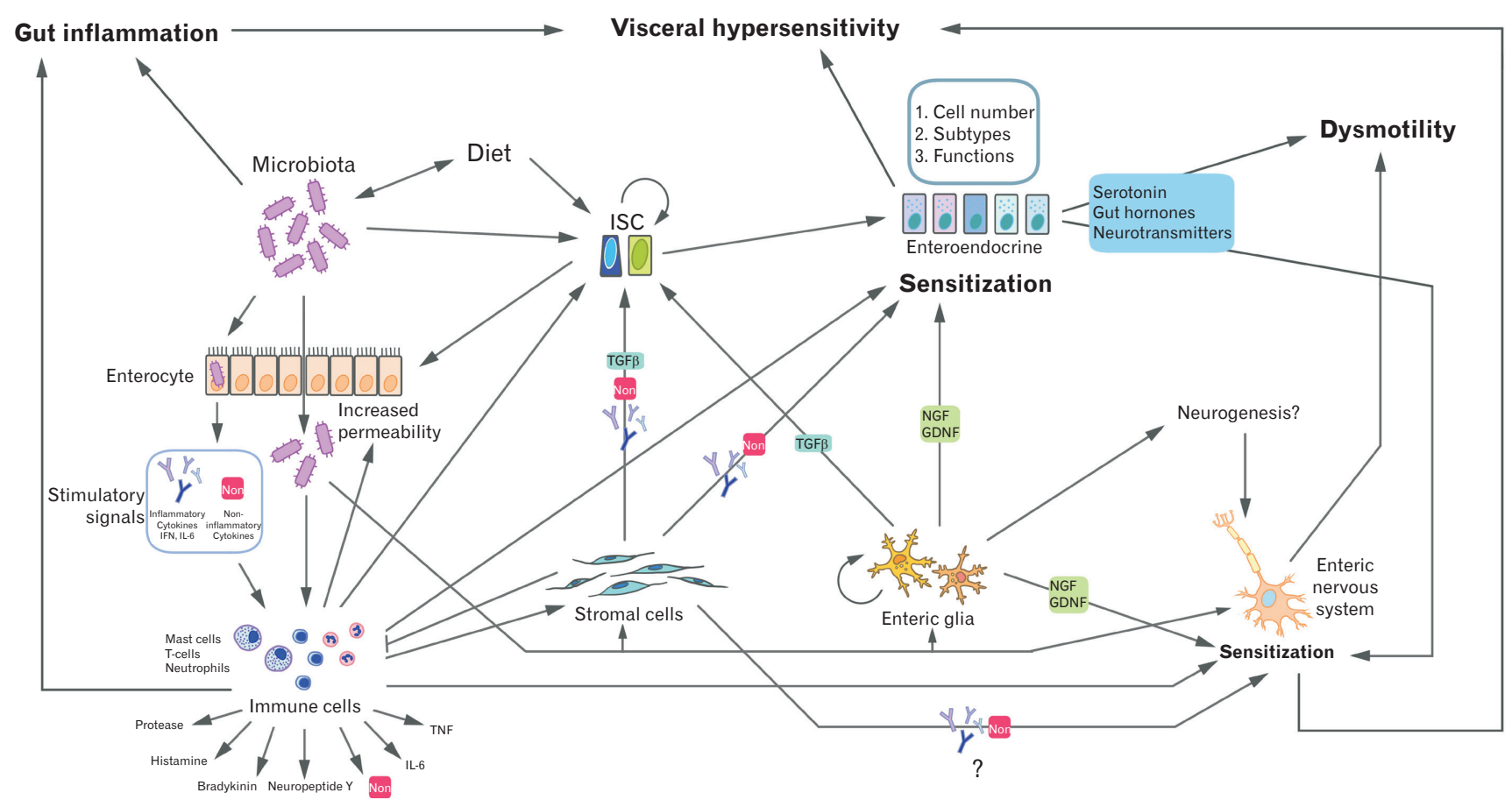

Figure 4. Pathogenesis of irritable bowel syndrome (IBS). In IBS context, external factors such as diet and microbiota can affect intestinal stem cells, niche cells, enteric glia and neurons, as well as immune cells. The resulting increased permeability and production of stimulatory signals, both inflammatory cytokines and other signaling molecules, disrupt intestinal homeostasis, leading to sensitization of the enteroendocrine and enteric nervous system. In particular, changes in enteroendocrine number, subtypes, and functions result in altered levels of neuropeptides and hormones, inducing hypersensitivity and dysmotility.

specific enteroendocrine subtypes has been documented. ${ }^{141} \mathrm{~A}$ reduction in the number of 5-HT producing enterochromaffin cells has been demonstrated in IBS-C. The densities of cell producing 5-HT and CCK were found to be increased in the small bowel of patients with PI-IBS and IBS-D. ${ }^{142}$ A decrease in the density of cells producing secretin and CCK has been observed in the small intestine of patients with IBS-D. Unlike many endocrine cells in different organs which turnover slowly, enteroendocrine cells actively self-renew and differentiate throughout life. Due to the relaxed chromatin state of the ISCs and progenitors, these cells can switch fate choice upon exposure to strong stimuli. It was shown that a subpopulation of mucosal T-lymphocytes can increase the number of enteroendocrine cells partly through IL-13. ${ }^{143}$ Other extrinsic factors such as diet and intestinal bacterial flora have been reported to affect the density and the secretory function of endocrine cells in the gut. ${ }^{141,144}$ It has been demonstrated that high fat diet decreased expression of transcription factors MATH1, NEUROG3, and NEUROD1, all of which are crucial for neuroendocrine cell differentiation and led to a decrease in number of enteroendocrine cells. $^{145}$
Strong developmental signals such as Notch, Wnt, and BMP could also play a role in various steps of enteroendocrine subtype specification and differentiation. Increased Notch signaling could promote enterocyte differentiation while inhibiting secretory cell fate. Ngn3, an important transcription factor for neuroendocrine differentiation, could also be inhibited by Notch mediator Hes-1. ${ }^{146}$ In mouse model, activation of Wnt in the early stage of neuroendocrine differentiation resulted in small-intestinal adenomas expressing serotonin. ${ }^{147}$

In contrast, it has been shown that the Wnt-coreceptor, lowdensity lipoproteinreceptor-related protein 5 (LRP5), inhibits the production of 5-HT from gut enterochromaffin cells by inhibiting expression of tryptophan hydroxylase 1 , the rate-limiting biosynthetic enzyme for serotonin. ${ }^{148}$ Although the roles of TGF- $\beta / \mathrm{BMP}$ signaling on enteroendocrine differentiation have not been extensively studied in ISCs, deletion of epithelial BMP in the gastric epithelium significantly increased the number of Chromogranin A, Ghrelin, Somatostatin, Gastrin, and 5-HT expressing gastric endocrine cells. ${ }^{149}$ It has also been predicted that Pax4, another important transcription factor in enteroendocrine subtype specification 
requires the TGF/BMP mediator Smad for co-regulation of its target genes. ${ }^{150}$

Secretion of each type of enteroendocrine cell is triggered by specific luminal contents, hormones and the enteric nervous system. Gut microbiota can influence 5-HT release by producing shortchain fatty acids stimulating FFA2 receptors on enterochromaffin cells. Enteroendocrine cells also express TRPA1, a member of the transient receptor potential (TRP) family of ion channel, which plays a role in sensing mechanical, chemical, and thermal stimulation. ${ }^{151}$ Mechanical stimulation such as bowel distension is a strong inducer of enteroendocrine secretion. Sensitivity of TRP receptors can be modulated by inflammatory cytokines, hormones and neurotropic factors such as GDNF and NGF. TNF can also potentiate mechanical sensitivity of TRPA1 $1{ }^{152}$ Proteases released from mast cells, calcitonin gene-related peptide (CGRP) and neuropeptide Y are known to be key players in pain sensitization. Wnt can induce pain hypersensitivity through the $\beta$-catenin independent pathway. Hypersensitivity of enteroendocrine cells to subthreshold stimuli frequently occurs transiently after infection/inflammation but may persist for a long period of time in some patients. The mechanism responsible for the persistent change is important and still needs to be elucidated.

Enteric nervous system hypersensitivity has been proposed to be a key event in IBS pathogenesis. Stimulation of afferent fibers of the enteric nervous system with 5-HT in combination with histamine, bradykinin, prostaglandin, and other inflammatory cytokines can activate previously silent units. ${ }^{152}$ It was shown that even mild transient upregulation of inflammatory cytokines could lead to chronic hypersensitivity. ${ }^{153}$ Inflammatory- induced neuroplasticity change can persist long after the inflammation subsides. ${ }^{154}$ It should be noted that non-immune cells could also contribute signals to the process of sensitization. Enteric glial cells and smooth muscle cells produce GDNF and NGF, which in turn, promote neuropeptide $\mathrm{Y}$ and CGRP release from enteric neurons. ${ }^{155}$ These cytokines are known to be responsible for neurogenic inflammation and peripheral sensitization in a number of chronic pain syndromes such as migraine. ${ }^{65}$

Mesenchymal stromal cells can produce either pro-inflammatory cytokines such as IL-1 $\beta$, TNF- $\alpha$ or anti-inflammatory cytokines such as IL-10 and TGF- $\beta$ depending on the environmental signals. TGF- $\beta 2$ was shown to be capable of stimulating neural outgrowth of cultured myenteric neurons. ${ }^{156}$ Stromal cells also secrete Wnt which can regulate the expression of glutamate receptors in the sensory neurons. ${ }^{111}$ Recent findings suggest that upon stimulation with injury signals, the enteric nervous system may stimulate neurogenesis by reversing enteric glia to a progenitor state. ${ }^{157,158}$ Such progenitors then produce new neurons. Whether adult neurogenesis is even partially responsible for long-term plasticity is still a matter of debate. It remains unclear whether this phenomenon occurs in vivo. Nevertheless, our understanding of the neural plasticity in IBS could lead to new therapeutic interventions.

\section{Conclusion}

In this review we have discussed how ISCs and abnormalities in regulatory pathways may be involved in the pathogenesis and symptom development of IBD and a subpopulation of IBS. Future studies on the changes in these pathways in IBS patients may open up a new approach for more effective therapeutic intervention of these common diseases.

Acknowledgements: Authors thank Fern Chanduayvit for illustrations.

\section{Financial support: None.}

\section{Conflicts of interest: None.}

\section{References}

1. Barker N. Adult intestinal stem cells: critical drivers of epithelial homeostasis and regeneration. Nat Rev Mol Biol 2014;15:19-33.

2. Pott J, Hornef M. Innate immune signalling at the intestinal epithelium in homeostasis and disease. EMBO Rep 2012;13:684-698.

3. Birchenough GM, Johansson ME, Gustafsson JK, Bergstrom JH, Hansson GC. New developments in goblet cell mucus secretion and function. Mucosal Immunol 2015;8:712-719.

4. Clevers HC, Bevins CL. Paneth cells: maestros of the small intestinal crypts. Annual Rev Physiol 2013;75:289-311.

5. Sato T, van Es JH, Snippert HJ, et al. Paneth cells constitute the niche for Lgr5 stem cells in intestinal crypts. Nature 2011;469:415-418.

6. Zhang H, Yan Y, Shi R, Lin Z, Wang M, Lin L. Correlation of gut hormones with irritable bowel syndrome. Digestion 2008;78:72-76.

7. Van Der Veek PP, Biemond I, Masclee AA. Proximal and distal gut hormone secretion in irritable bowel syndrome. Scand J Gastroenterol 2006;41:170-177

8. Ogiso K, Asakawa A, Amitani H, Inui A. Ghrelin: a gut hormonal basis of motility regulation and functional dyspepsia. J Gastroenterol Hepatol 2011;26(suppl 3):67-72.

9. Lake JI, Heuckeroth RO. Enteric nervous system development: migration, differentiation, and disease. Am J Physiol Gastrointest Liver Physiol 2013;305:G1-G24

10. Yu YB, Li YQ. Enteric glial cells and their role in the intestinal epithelial 
barrier. World J Gastrolenterol 2014;20:11273-11280.

11. Kabiri Z, Greicius G, Madan B, et al. Stroma provides an intestinal stem cell niche in the absence of epithelial Wnts. Development 2014;141:2206-2215.

12. Owens BM. Inflammation, innate immunity, and the intestinal stromal cell niche: opportunities and challenges. Front Immunol 2015;6:319.

13. Lindemans $\mathrm{CA}$, Calafiore M, Mertelsmann AM, et al. Interleukin-22 promotes intestinal-stem-cell-mediated epithelial regeneration. Nature 2015;528:560-564.

14. Cosin-Roger J, Ortiz-Masia D, Calatayud S, Hernandez C, Esplugues JV, Barrachina MD. The activation of Wnt signaling by a STAT6dependent macrophage phenotype promotes mucosal repair in murine IBD. Mucosal immunol Published Online Fist: doi: 10.1038/ mi.2015.123.

15. Dahan S, Roda G, Pinn D, et al. Epithelial: lamina propria lymphocyte interactions promote epithelial cell differentiation. Gastroenterology 2008;134:192-203.

16. Okamoto R, Watanabe M. Role of epithelial cells in the pathogenesis and treatment of inflammatory bowel disease. J Gastroenterol 2016;5 1:11-21.

17. Leblond CP, Stevens CE. The constant renewal of the intestinal epithelium in the albino rat. Anat Rec 1948;100:357-377.

18. Scoville DH, Sato T, He XC, Li L. Current view: intestinal stem cells and signaling. Gastroenterology 2008;134:849-864.

19. Sancho R, Cremona CA, Behrens A. Stem cell and progenitor fate in the mammalian intestine: notch and lateral inhibition in homeostasis and disease. EMBO Rep 2015;16:571-581.

20. Bjerknes $M$, Cheng $H$. The stem-cell zone of the small intestinal epithelium. I. Evidence from Paneth cells in the adult mouse. Am J Anat 1981;160:51-63.

21. Barker N, van Es JH, Kuipers J, et al. Identification of stem cells in small intestine and colon by marker gene Lgr5. Nature 2007;449:10031007.

22. Sato T, Vries RG, Snippert HJ, et al. Single Lgr5 stem cells build crypt-villus structures in vitro without a mesenchymal niche. Nature 2009;459:262-265.

23. Potten CS, Kovacs L, Hamilton E. Continuous labelling studies on mouse skin and intestine. Cell Tissue Kinet 1974;7:271-283.

24. Kosinski C, Li VS, Chan AS, et al. Gene expression patterns of human colon tops and basal crypts and BMP antagonists as intestinal stem cell niche factors. Proc Natl Acad Sci USA 2007;104:15418-15423.

25. Metcalfe C, Kljavin NM, Ybarra R, de Sauvage FJ. Lgr 5 + stem cells are indispensable for radiation-induced intestinal regeneration. Cell Stem Cell 2014;14:149-159.

26. Takeda N, Jain R, LeBoeuf MR, Wang Q, Lu MM, Epstein JA. Interconversion between intestinal stem cell populations in distinct niches. Science 2011;334:1420-1424.

27. Tetteh PW, Farin HF, Clevers H. Plasticity within stem cell hierarchies in mammalian epithelia. Trends Cell Biol 2015;25:100-108.

28. van Es JH, Sato T, van de Wetering M, et al. Dll1 + secretory progenitor cells revert to stem cells upon crypt damage. Nat Cell Biol 2012;14: 1099-1104.

29. Buczacki SJ, Zecchini HI, Nicholson AM, et al. Intestinal label-retain- ing cells are secretory precursors expressing Lor5. Nature 2013;495:6569.

30. Roth S, Franken P, Sacchetti A, et al. Paneth cells in intestinal homeostasis and tissue injury. PLoS One 2012;7:e38965.

31. Basak O, van de Born M, Korving J, et al. Mapping early fate determination in Lgr5 + crypt stem cells using a novel Ki67-RFP allele. EMBO J 2014;33:2057-2068.

32. Gehart $\mathrm{H}$, Clevers $\mathrm{H}$. Repairing organs: lessons from intestine and liver. Trends Genet 2015;31:344-351.

33. Bjerknes M, Cheng $H$. The stem-cell zone of the small intestinal epithelium. III. Evidence from columnar, enteroendocrine, and mucous cells in the adult mouse. Am J Anat 1981;160:77-91.

34. Wang JC, Harris WA. The role of combinational coding by homeodomain and bHLH transcription factors in retinal cell fate specification. Dev Biol 2005;285:101-115.

35. Li HJ, Ray SK, Singh NK, Johnston B, Leiter AB. Basic helix-loophelix transcription factors and enteroendocrine cell differentiation. Diabetes Obes Matab 2011;13(suppl 1):5-12.

36. Yang Q, Bermingham NA, Finegold MJ, Zoghbi HY. Requirement of Math1 for secretory cell lineage commitment in the mouse intestine. Science 2001;294:2155-2158.

37. VanDussen KL, Samuelson LC. Mouse atonal homolog 1 directs intestinal progenitors to secretory cell rather than absorptive cell fate. Dev Biol 2010;346:215-223.

38. Shroyer NF, Wallis D, Venken KJ, Bellen HJ, Zoghbi HY. Gfi1 functions downstream of Math1 to control intestinal secretory cell subtype allocation and differentiation. Genes Dev 2005;19:2412-2417.

39. Beucher A, Gjernes E, Collin C, et al. The homeodomain-containing transcription factors Arx and $\mathrm{Pax} 4$ control enteroendocrine subtype specification in mice. PLoS One 2012;7:e36449.

40. Beehler-Evans R, Micchelli CA. Generation of enteroendocrine cell diversity in midgut stem cell lineages. Development 2015;142:654-664.

41. Schwitzgebel VM, Scheel DW, Conners JR, et al. Expression of neurogenin 3 reveals an islet cell precursor population in the pancreas. Development 2000;127:3533-3542.

42. López-Díaz L, Jain RN, Keeley TM, et al. Intestinal Neurogenin 3 directs differentiation of a bipotential secretory progenitor to endocrine cell rather than goblet cell fate. Dev Biol 2007;309:298-305.

43. Mutoh H, Naya FJ, Tsai MJ, Leiter AB. The basic helix-loop-helix protein BETA2 interacts with $\mathrm{p} 300$ to coordinate differentiation of secretin-expressing enteroendocrine cells. G Enes Dev 1998;12:820-830.

44. Huang HP, Liu M, El-Hodiri HM, Chu K, Jamrich M, Tsai MJ. Regulation of the pancreatic islet-specific gene BETA2 (neuroD) by neurogenin 3. Mol Cell Biol 2000;20:3292-3307.

45. Wang J, Cortina G, Wu SV, et al. Mutant neurogenin-3 in congenital malabsorptive diarrhea. N Engl J Med 2006;355:270-280.

46. Fishbein TM, Novitskiy G, Lough DM, et al. Rejection reversibly alters enteroendocrine cell renewal in the transplanted small intestine. Am J Transplant 2009;9:1620-1628.

47. Biswas S, Davis H, Irshad S, Sandberg T, Worthley D, Leedham S. Microenvironmental control of stem cell fate in intestinal homeostasis and disease. J Pathol 2015;237:135-145. 
48. de Lau W, Barker N, Low TY, et al. Lgr5 homologues associate with Wnt receptors and mediate R-spondin signalling. Nature 2011;476:293297.

49. Haramis AP, Begthel H, van den Born M, et al. De novo crypt formation and juvenile polyposis on BMP inhibition in mouse intestine. Science 2004;303:1684-1686.

50. Pellegrinet L, Rodilla V, Liu Z, et al. Dll1- and dll4-mediated notch signaling are required for homeostasis of intestinal stem cells. Gastroenterology 2011;140:1230-1240, e1-e7.

51. van der Flier LG, van Gijn ME, Hatzis P, et al. Transcription factor achaete scute-like 2 controls intestinal stem cell fate. Cell 2009;136:903912.

52. Riccio O, van Gijn ME, Bezdek AC, et al. Loss of intestinal crypt progenitor cells owing to inactivation of both Notch1 and Notch2 is accompanied by derepression of CDK inhibitors p27Kip1 and p57Kip2. EMBO Rep 2008;9:377-383.

53. van Es JH, van Gijn ME, Riccio O, et al. Notch/gamma-secretase inhibition turns proliferative cells in intestinal crypts and adenomas into goblet cells. Nature 2005;435:959-963.

54. Noah TK, Shroyer NF. Notch in the intestine: regulation of homeostasis and pathogenesis. Annu Rev Physiol 2013;75:263-288.

55. Mathern DR, Laitman LE, Hovhannisyan Z, et al. Mouse and human Notch-1 regulate mucosal immune responses. Mucosal Immunol 2014;7:995-1005.

56. Obata Y, Takahashi D, Ebisawa M, et al. Epithelial cell-intrinsic Notch signaling plays an essential role in the maintenance of gut immune homeostasis. J Immunol 2012;188:2427-2436.

57. Guilmeau S, Flandez M, Bancroft L, et al. Intestinal deletion of Pofut1 in the mouse inactivates notch signaling and causes enterocolitis. Gastroenterology 2008;135:849-860, e1-e6.

58. Okamoto R, Tsuchiya K, Nemoto Y, et al. Requirement of Notch activation during regeneration of the intestinal epithelia. Am J Physiol Gastrointest Liver Physiol 2009;296:G23-G35.

59. Tsai YH, VanDussen KL, Sawey ET, et al. ADAM10 regulates Notch function in intestinal stem cells of mice. Gastroenterology 2014;147:822834.e13.

60. Ueo T, Imayoshi I, Kobayashi T, et al. The role of Hes genes in intestinal development, homeostasis and tumor formation. Development 2012;139:1071-1082.

61. Yang Y, Zhu R, Bai J, et al. Numb modulates intestinal epithelial cells toward goblet cell phenotype by inhibiting the Notch signaling pathway. Exp Cell Res 2011;317:1640-1648.

62. Shimizu H, Okamoto R, Ito G, et al. Distinct expression patterns of Notch ligands, Dll1 and Dll4, in normal and inflamed mice intestine. PeerJ 2014;2:e370.

63. D'Souza B, Miyamoto A, Weinmaster G. The many facets of Notch ligands. Oncogene 2008;27:5148-5167.

64. Bozkulak EC, Weinmaster G. Selective use of ADAM10 and ADAM17 in activation of Notch1 signaling. Mol Cell Biol 2009;29:5679-5695.

65. Cesaro A, Abakar-Mahamat A, Brest P, et al. Differential expression and regulation of ADAM17 and TIMP3 in acute inflamed intestinal epithelia. Am J Physiol Gastrointest Liver Physiol 2009;296:G1332-G1343.
66. Fréour T, Jarry A, Bach-Ngohou K, et al. TACE inhibition amplifies TNF-alpha-mediated colonic epithelial barrier disruption. Int J Mol Med 2009;23:41-48.

67. Korinek V, Barker N, Moerer P, et al. Depletion of epithelial stem-cell compartments in the small intestine of mice lacking Tcf-4. Nat Genet 1998;19:379-383.

68. Pinto D, Gregorieff A, Begthel H, Clevers H. Canonical Wnt signals are essential for homeostasis of the intestinal epithelium. Genes Dev 2003;17:1709-1713.

69. Toledo EM, Colombres M, Inestrosa NC. Wnt signaling in neuroprotection and stem cell differentiation. Prog Neurobiol 2008;86:281-296.

70. Inestrosa NC, Arenas E. Emerging roles of Wnts in the adult nervous system. Nat Rev Neurosci 2010;11:77-86.

71. van Es JH, Haegebarth A, Kujala P, et al. A critical role for the Wnt effector Tcf4 in adult intestinal homeostatic self-renewal. Mol Cell Biol 2012;32:1918-1927.

72. Schuijers J, Junker JP, Mokry M, et al. Ascl2 acts as an R-spondin/ Wnt-responsive switch to control stemness in intestinal crypts. Cell Stem Cell 2015;16:158-170.

73. Hoffman J, Kuhnert F, Davis CR, Kuo CJ. Wnts as essential growth factors for the adult small intestine and colon. Cell Cycle 2004;3:554557.

74. Miyoshi H, Ajima R, Luo CT, Yamaguchi TP, Stappenbeck TS. Wnt5a potentiates TGF- $\beta$ signaling to promote colonic crypt regeneration after tissue injury. Science 2012;338:108-113.

75. Hughes KR, Sablitzky F, Mahida YR. Expression profiling of Wnt family of genes in normal and inflammatory bowel disease primary human intestinal myofibroblasts and normal human colonic crypt epithelial cells. Inflamm Bowel Dis 2011;17:213-220.

76. Sugimura R, He XC, Venkatraman A, et al. Noncanonical Wnt signaling maintains hematopoietic stem cells in the niche. Cell 2012;150:351365.

77. de Lau WB, Snel B, Clevers HC. The R-spondin protein family. Genome Biol 2012;13:242.

78. Gregorieff A, Pinto D, Begthel H, Destrée O, Kielman M, Clevers H. Expression pattern of Wnt signaling components in the adult intestine. Gastroenterology 2005;129:626-638.

79. Heuberger J, Kosel F, Qi J, Grossmann KS, Rajewsky K, Birchmeier W. Shp2/MAPK signaling controls goblet/paneth cell fate decisions in the intestine. Proc Natl Acad Sci USA 2014;111:3472-3477.

80. Le Guen L, Marchal S, Faure S, de Santa Barbara P. Mesenchymalepithelial interactions during digestive tract development and epithelial stem cell regeneration. Cell Mol Life Sci 2015;72:3883-3896.

81. Bezerra Lima B, Faria Fonseca B, da Graça Amado N, et al. Clostridium difficile toxin A attenuates Wnt/ $\beta$-catenin signaling in intestinal epithelial cells. Infect Immun 2014;82:2680-2687.

82. Liu Z, Brooks RS, Ciappio ED, et al. Diet-induced obesity elevates colonic TNF- $\alpha$ in mice and is accompanied by an activation of Wnt signaling: a mechanism for obesity-associated colorectal cancer. J Natr Ciochem 2012;23:1207-1213

83. Koch S, Nava P, Addis C, et al. The Wnt antagonist Dkk1 regulates intestinal epithelial homeostasis and wound repair. Gastroenterology 
2011;141:259-268, e1-e8.

84. Simonetti M, Agarwal N, Stosser S, et al. Wnt-Fzd signaling sensitizes peripheral sensory neurons via distinct noncanonical pathways. Neuron 2014;83:104-121.

85. Tian H, Biehs B, Chiu C, et al. Opposing activities of Notch and Wnt signaling regulate intestinal stem cells and gut homeostasis. Cell Rep 2015;11:33-42.

86. Axelrod JD, Matsuno K, Artavanis-Tsakonas S, Perrimon N. Interaction between Wingless and Notch signaling pathways mediated by dishevelled. Science 1996;271:1826-1832.

87. Schweisguth F. Regulation of notch signaling activity. Current biology 2004;14:R129-R138.

88. Oshimori N, Fuchs E. The harmonies played by TGF- $\beta$ in stem cell biology. Cell Stem Cell 2012;11:751-764.

89. Massagué J. TGF $\beta$ signalling in context. Nat Rev Mol Cell Biol 2012;13:616-630.

90. Kalluri R, Weinberg RA. The basics of epithelial-mesenchymal transition. J Clin Invest 2009;119:1420-1428.

91. He XC, Zhang J, Tong WG, et al. BMP signaling inhibits intestinal stem cell self-renewal through suppression of Wnt- $\beta$-catenin signaling. Nat Genet 2004;36:1117-1121.

92. Du H, Nie Q, Holmes WR. The interplay between Wnt mediated expansion and negative regulation of growth promotes robust intestinal crypt structure and homeostasis. PLoS Comput Biol 2015;11:e1004285.

93. Davis H, Irshad S, Bansal M, et al. Aberrant epithelial GREM1 expression initiates colonic tumorigenesis from cells outside the stem cell niche. Nat Med 2015;21:62-70.

94. Auclair BA, Benoit YD, Rivard N, Mishina Y, Perreault N. Bone morphogenetic protein signaling is essential for terminal differentiation of the intestinal secretory cell lineage. Gastroenterology 2007;133:887-896.

95. Dignass AU, Podolsky DK. Cytokine modulation of intestinal epithelial cell restitution: central role of transforming growth factor beta. Gastroenterology 1993;105:1323-1332.

96. Sedda S, Marafini I, Dinallo V, Di Fusco D, Monteleone G. The TGF- $\beta /$ Smad system in IBD pathogenesis. Inflamm Bowel Dis 2015;21:2921-2925.

97. Sheehan D, Moran C, Shanahan F. The microbiota in inflammatory bowel disease. J Gastroenterol 2015;50:495-507.

98. Maloy KJ, Powrie F. Intestinal homeostasis and its breakdown in inflammatory bowel disease. Nature 2011;474:298-306.

99. Heazlewood CK, Cook MC, Eri R, et al. Aberrant mucin assembly in mice causes endoplasmic reticulum stress and spontaneous inflammation resembling ulcerative colitis. PLoS Med 2008;5:e54.

100. Van der Sluis M, De Koning BA, De Bruijn AC, et al. Muc2-deficient mice spontaneously develop colitis, indicating that MUC2 is critical for colonic protection. Gastroenterology 2006;131:117-129.

101. Hugot JP, Chamaillard M, Zouali H, et al. Association of NOD2 leucine-rich repeat variants with susceptibility to Crohn's disease. Nature 2001;411:599-603.

102. Ogura Y, Bonen DK, Inohara N, et al. A frameshift mutation in NOD2 associated with susceptibility to Crohn's disease. Nature 2001;411:603606.
103. Adolph TE, Tomczak MF, Niederreiter L, et al. Paneth cells as a site of origin for intestinal inflammation. Nature 2013;503:272-276.

104. Khor B, Gardet A, Xavier RJ. Genetics and pathogenesis of inflammatory bowel disease. Nature 2011;474:307-317.

105. Park ET, Oh HK, Gum JR Jr, et al. HATH1 expression in mucinous cancers of the olorectum and related lesions. Clin Cancer Res 2006;12:5403-5410.

106. Shinoda M, Shin-Ya M, Naito Y, et al. Early-stage blocking of Notch signaling inhibits the depletion of goblet cells in dextran sodium sulfateinduced colitis in mice. J Gastroenterol 2010;45:608-617.

107. Nava P, Koch S, Laukoetter MG, et al. Interferon- $\gamma$ regulates intestinal epithelial homeostasis through converging $\beta$-catenin signaling pathways. Immunity 2010;32:392-402.

108. Beisner J, Teltschik Z, Ostaff MJ, et al. TCF-1-mediated Wnt signaling regulates Paneth cell innate immune defense effectors HD-5 and -6: implications for Crohn's disease. Am J Physiol Gastrointest Liver Physiol 2014;307:G487-G498.

109. Di Liddo R, Bertalot T, Schuster A, et al. Anti-inflammatory activity of Wnt signaling in enteric nervous system: in vitro preliminary evidences in rat primary cultures. J Neuroinflammation 2015;12:23.

110. Sen M, Ghosh G. Transcriptional outcome of Wnt-Frizzled signal transduction in inflammation: evolving concepts. J Immunol 2008;181:44414445.

111. Cerpa W, Ramos-Fernández E, Inestrosa NC. Modulation of the NMDA receptor through secreted soluble factors. Mol Neurobiol 2016;53:299-309.

112. Del Zotto B, Mumolo G, Pronio AM, Montesani C, Tersigni R, Boirivant $\mathrm{M}$. TGF- $\beta 1$ production in inflammatory bowel disease: differing production patterns in Crohn's disease and ulcerative colitis. Clin Exp Immunol 2003;134:120-126.

113. Fiocchi C. TGF- $\beta /$ Smad signaling defects in inflammatory bowel disease: mechanisms and possible novel therapies for chronic inflammation. J Clin Invest 2001;108:523-526.

114. Monteleone G, Boirivant M, Pallone F, MacDonald TT. TGF- $\beta 1$ and Smad7 in the regulation of IBD. Mucosal Immunol 2008;1(suppl 1): S50-S53.

115. Monteleone G, Kumberova A, Croft NM, McKenzie C, Steer HW, MacDonald TT. Blocking Smad7 restores TGF- $\beta 1$ signaling in chronic inflammatory bowel disease. J Clin Invest 2001;108:601-609.

116. Boirivant M, Pallone F, Di Giacinto C, et al. Inhibition of Smad7 with a specific antisense oligonucleotide facilitates TGF- $\beta 1$-mediated suppression of colitis. Gastroenterology 2006;131:1786-1798.

117. Monteleone G, Neurath MF, Ardizzone S, et al. Mongersen, an oral SMAD7 antisense oligonucleotide, and Crohn's disease. N Engl J Med 2015;372:1104-1113.

118. Maric I, Kucic N, Turk Wensveen T, et al. BMP signaling in rats with TNBS-induced colitis following BMP7 therapy. Am J Physiol Gastroinest Liver Physiol 2012;302:G1151-G1162.

119. Yui S, Nakamura T, Sato T, et al. Functional engraftment of colon epithelium expanded in vitro from a single adult $\operatorname{Lgr} 5^{+}$stem cell. Nat Med 2012;18:618-623.

120. Fordham RP, Yui S, Hannan NR, et al. Transplantation of expanded 
fetal intestinal progenitors contributes to colon regeneration after injury. Cell Stem Cell 2013;13:734-744.

121. Okamoto R, Watanabe M. Perspectives for regenerative medicine in the treatment of inflammatory bowel diseases. Digestion 2015;92:73-77.

122. Ke C, Biao H, Qianqian L, Yunwei S, Xiaohua J. Mesenchymal stem cell therapy for inflammatory bowel diseases: promise and challenge. Curr Stem Cell Res Ther 2015;10:499-508.

123. Barbara $G$, Cremon $C$, Carini $G$, et al. The immune system in irritable bowel syndrome. J Neurogastoenterol Motil 2011;17:349-359.

124. Bellini M, Gambaccini D, Stasi C, Urbano MT, Marchi S, Usai-Satta P. Irritable bowel syndrome: a disease still searching for pathogenesis, diagnosis and therapy. World J Gastroenterol 2014;20:8807-8820.

125. Bennet SM, Ohman L, Simren M. Gut microbiota as potential orchestrators of irritable bowel syndrome. Gut Liver 2015;9:318-331.

126. El-Salhy M. Recent developments in the pathophysiology of irritable bowel syndrome. World J Gastroenterol 2015;21:7621-7636.

127. Ohman L, Simrén M. Pathogenesis of IBS: role of inflammation, immunity and neuroimmune interactions. Nat Rev Gastroenterol Hepatol 2010;7:163-173.

128. El-Salhy M, Gundersen D, Hatlebakk JG, Hausken T. Low-grade inflammation in the rectum of patients with sporadic irritable bowel syndrome. Mol Med Rep 2013;7:1081-1085.

129. Lee YJ, Park KS. Irritable bowel syndrome: emerging paradigm in pathophysiology. World J Gastroenterol 2014;20:2456-2469.

130. Thabane M, Kottachchi DT, Marshall JK. Systematic review and metaanalysis: The incidence and prognosis of post-infectious irritable bowel syndrome. Aliment Pharmacol Ther 2007;26:535-544.

131. Zanini B, Ricci C, Bandera F, et al. Incidence of post-infectious irritable bowel syndrome and functional intestinal disorders following a waterborne viral gastroenteritis outbreak. Am J Gastroenterol 2012;107:891899.

132. Liebregts T, Adam B, Bredack C, et al. Immune activation in patients with irritable bowel syndrome. Gastroenterology 2007;132:913-920.

133. Öhman L, Törnblom H, Simrén M. Crosstalk at the mucosal border: importance of the gut microenvironment in IBS. Nat Rev Gastroenterol Hepatol 2015;12:36-49.

134. Piche T. Tight junctions and IBS--the link between epithelial permeability, low-grade inflammation, and symptom generation? Neurogastroenterol Motil 2014;26:296-302.

135. Karaki S, Mitsui R, Hayashi H, et al. Short-chain fatty acid receptor, $\mathrm{GPR}_{43}$, is expressed by enteroendocrine cells and mucosal mast cells in rat intestine. Cell Tissue Res 2006;324:353-360.

136. Schwanbeck R. The role of epigenetic mechanisms in Notch signaling during development. J Cell Physiol 2015;230:969-981.

137. Katoh M. WNT signaling in stem cell biology and regenerative medicine. Curr Drug Targets 2008;9:565-570.

138. Manocha M, Khan WI. Serotonin and GI disorders: an update on clinical and experimental studies. Clin Transl Gastroenterol 2012;3:e13.

139. Atkinson W, Lockhart S, Whorwell PJ, Keevil B, Houghton LA. Altered 5-hydroxytryptamine signaling in patients with constipationand diarrhea-predominant irritable bowel syndrome. Gastroenterology 2006;130:34-43.
140. Wang YM, Chang Y, Chang YY, et al. Serotonin transporter gene promoter region polymorphisms and serotonin transporter expression in the colonic mucosa of irritable bowel syndrome patients. Neurogastroenterol Motil 2012;24:560-565, e254-e255.

141. El-Salhy M, Gilja OH, Gundersen D, Hatlebakk JG, Hausken T. Interaction between ingested nutrients and gut endocrine cells in patients with irritable bowel syndrome (review). Int J Mol Med 2014;34:363371.

142. Dunlop SP, Jenkins D, Neal KR, Spiller RC. Relative importance of enterochromaffin cell hyperplasia, anxiety, and depression in postinfectious IBS. Gastroenterology 2003;125:1651-1659.

143. Wang H, Steeds J, Motomura Y, et al. CD4 ${ }^{+}$T cell-mediated immunological control of enterochromaffin cell hyperplasia and 5-hydroxytryptamine production in enteric infection. Gut 2007;56:949-957.

144. Neunlist M, Schemann M. Nutrient-induced changes in the phenotype and function of the enteric nervous system. J Physiol 2014;592:29592965.

145. Sakar Y, Duca FA, Langelier B, et al. Impact of high-fat feeding on basic helix-loop-helix transcription factors controlling enteroendocrine cell differentiation. Int J Obes (Lond) 2014;38:1440-1448.

146. Lee JC, Smith SB, Watada H, et al. Regulation of the pancreatic proendocrine gene neurogenin3. Diabetes 2001;50:928-936.

147. Wang Y, Giel-Moloney M, Rindi G, Leiter AB. Enteroendocrine precursors differentiate independently of Wnt and form serotonin expressing adenomas in response to active $\beta$-catenin. Proc Natl Acad Sci USA 2007; 104:11328-11333.

148. Yadav VK, Ryu JH, Suda N, et al. Lrp5 controls bone formation by inhibiting serotonin synthesis in the duodenum. Cell 2008;135:825-837.

149. Maloum F, Allaire JM, Gagné-Sansfaçon J, et al. Epithelial BMP signaling is required for proper specification of epithelial cell lineages and gastric endocrine cells. Am J Physiol Gastrointest Liver Physiol 2011;300:G1065-G1079.

150. Qin H, Chan MW, Liyanarachchi S, et al. An integrative ChIP-chip and gene expression profiling to model SMAD regulatory modules. BMC Syst Biol 2009;3:73.

151. Boesmans W, Owsianik G, Tack J, Voets T, Vanden Berghe P. TRP channels in neurogastroenterology: opportunities for therapeutic intervention. Br J Pharmacol 2011;162:18-37.

152. Hughes PA, Harrington AM, Castro J, et al. Sensory neuro-immune interactions differ between irritable bowel syndrome subtypes. Gut 2013;62:1456-1465.

153. Keszthelyi D, Troost FJ, Simren M, et al. Revisiting concepts of visceral nociception in irritable bowel syndrome. Eur J Pain 2012;16:1444-1454.

154. Mawe GM. Colitis-induced neuroplasticity disrupts motility in the inflamed and post-inflamed colon. J Clin Invest 2015;125:949-955.

155. Brun P, Gobbo S, Caputi V, et al. Toll like receptor-2 regulates production of glial-derived neurotrophic factors in murine intestinal smooth muscle cells. Mol Cell Neurosci 2015;68:24-35.

156. Hagl C, Schafer KH, Hellwig I, et al. Expression and function of the Transforming Growth Factor-b system in the human and rat enteric nervous system. Neurogastroenterol Motil 2013;25:601-e464.

157. Laranjeira C, Sandgren K, Kessaris N, et al. Glial cells in the mouse 
enteric nervous system can undergo neurogenesis in response to injury. J Clin Invest 2011;121:3412-3424.

158. Joseph NM, He S, Quintana E, Kim YG, Núñez G, Morrison SJ.
Enteric glia are multipotent in culture but primarily form glia in the adult rodent gut. J Clin Invest 2011;121:3398-3411. 